\title{
Análise in vitro da atividade antifúngica de extratos vegetais frente a leveduras
} pertencentes à espécie Candida albicans

In vitro analysis of the antifungical activity of plant extracts against yeasts belongimg to the Candida albicans species

Análisis in vitro de la efectividad antifúngica de extractos vegetales frente a levaduras pertenecientes a la especie Candida albicans

Recebido: 04/08/2021 | Revisado: 07/08/2021 | Aceito: 12/08/2021 | Publicado: 15/08/2021

Lara Vitória de Araujo Costa Pereira ORCID: https://orcid.org/0000-0001-6946-4936 Centro Universitário Unifacid Wyden, Brasil E-mail: laravitoriaacp@ hotmail.com

Luciane Costa Silva

ORCID: https://orcid.org/0000-0003-0469-5092 Centro Universitário Unifacid Wyden, Brasil E-mail: costasilvaluciane2900@gmail.com

Marcela Coêlho de Sá

ORCID: https://orcid.org/0000-0002-3797-0997 Centro Universitário Unifacid Wyden, Brasil E-mail: marcelacoelhodesa0908@gmail.com

Mariana de Carvalho Moreira ORCID: https://orcid.org/0000-0002-6710-8994 Centro Universitário Unifacid Wyden, Brasil E-mail: maridecm93@gmail.com

Gabriel Lima Maia Soares do Nascimento ORCID: https://orcid.org/0000-0003-3666-635X Centro Universitário Unifacid Wyden, Brasil E-mail: glmaia64@hotmail.com Thaís Café de Andrade ORCID: https://orcid.org/0000-0002-2408-5649 Centro Universitário Unifacid Wyden, Brasil E-mail: thaiscaffe2@gmail.com

Vilma Marreiros dos Santos ORCID: https://orcid.org/0000-0002-8795-4442 Centro Universitário Unifacid Wyden E-mail: vilmamarreiros40mcap@ hotmail.com Francisco Laurindo da Silva ORCID: https://orcid.org/0000-0001-6837-4509 Centro Universitário Unifacid Wyden, Brasil E-mail: flspb@yahoo.com.br

\section{Resumo}

A candidíase é uma das afecções mais comuns, estimando-se que a grande parte das mulheres apresentará, ao longo da vida, pelo menos um episódio da infecção. E com isso a importância de estudos sobre outros métodos alternativos para tratamento baseados em extratos vegetais, os quais apresentam potencial ecológico para substituir o emprego de produtos sintéticos. Assim, a pesquisa teve como objetivo analisar a atividade antifúngica de extratos brutos dos vegetais Morinda citrifolia (None), Caryocar brasiliense (Pequi), Annona muricata(Graviola), Morus alba L. (Amora) e Apis mellífera L. (Própolis) frente a levedura Candida albicans. Os vegetais foram coletados no município de Teresina-PI e secos a temperatura ambiente sob a sombra, com exposição diária de $4 \mathrm{~h}$; moídos em moinho de facas; os extratos foram obtidos em metanol e os testes de suscetibilidade foram realizados em triplicata nos meios de cultura ágar-ágar e ágar Muller-Hinton, pela técnica da difusão em ágar. Utilizou-se a cepa de Candida albicans ATCC-76485 nos testes. Dos cinco vegetais utilizados, os extratos de Pequi e de Própolis, apresentaram atividade antifúngica sobre a cepa de $C$. albicans, com o segundo extrato apresentando maior poder de ação sobre a levedura. Portanto, os extratos do Apis melífera L. e do Caryocar brasiliense apresentaram atividade anti C. albicans, enquanto os de Morus alba L., Morinda citifolia L. e Annona muricata L. não apresentaram.

Palavras-chave: Extratos; Cepa; Candida albicans; Eficácia. 


\begin{abstract}
Candidiasis is one of the most common affections, and it is estimated that most women will present, throughout their lives, at least one episode of the infection. And with this the importance of studies on other alternative methods for treatment based on plant extracts, which have ecological potential to replace the use of synthetic products. Thus, the research aimed to analyze the antifungal activity of crude extracts of the vegetables Morinda citrifolia (None), Caryocar brasiliense (Pequi), Annona muricata (Graviola), Morus alba L. (Mora) and Apis mellifera L. (Propolis) in front of the yeast Candida albicans. The vegetables were collected in the municipality of Teresina-PI and dried at room temperature in the shade, with daily exposure of $4 \mathrm{~h}$; milled in knife mills; the extracts were obtained in methanol and the susceptibility tests were carried out in triplicate on agar-agar and Muller-Hinton agar culture media, using the agar diffusion technique. The Candida albicans ATCC-76485 strain was used in the tests. Of the five vegetables used, the extracts of Pequi and Propolis, showed antifungal activity on the strain of $C$. albicans, with the second extract showing greater power of action on the yeast. Therefore, extracts from Apis melifera L. and Caryocar brasiliense showed anti $C$. albicans activity, while those from Morus alba L., Morinda citifolia L. and Annona muricata $L$. did not.
\end{abstract}

Keywords: Extracts; Strain; Candida Albicans; Efficiency.

\begin{abstract}
Resumen
La candidiasis es una de las afecciones más comunes y se estima que la mayoría de las mujeres experimentarán al menos un episodio de infección a lo largo de su vida. Y con ello la importancia de los estudios sobre otros métodos alternativos de tratamiento basados en extractos de plantas, que tienen potencial ecológico para reemplazar el uso de productos sintéticos. Así, la investigación tuvo como objetivo analizar la actividad antifúngica de extractos crudos de las hortalizas Morinda citrifolia (Ninguno), Caryocar brasiliense (Pequi), Annona muricata (Graviola), Morus alba L. (Mora) y Apis mellifera L. (Propolis) en frente a la levadura Candida albicans. Las hortalizas se recolectaron en la ciudad de Teresina-PI y se secaron a temperatura ambiente a la sombra, con exposición diaria de 4 h; molido en molinos de cuchillos; los extractos se obtuvieron en metanol y las pruebas de sensibilidad se realizaron por triplicado en agar-agar y agar Muller-Hinton, utilizando la técnica de difusión en agar. En las pruebas se utilizó la cepa Candida albicans ATCC-76485. De las cinco verduras utilizadas, los extractos de Pequi y Propóleo, mostraron actividad antifúngica sobre la cepa de $C$. albicans, y el segundo extracto mostró mayor poder de acción sobre la levadura. Por tanto, los extractos de Apis mellifera L. y Caryocar brasiliense mostraron actividad anti C. albicans, mientras que los de Morus alba L., Morinda citifolia L. y Annona muricata L. no.
\end{abstract}

Palabras clave: Extractos; Cepa; Candida Albicans; Efectividad.

\title{
1. Introdução
}

O gênero Candida constitui o principal grupo de leveduras que causam infecções oportunistas no ser humano. Este gênero compõe-se de cerca de 150-200 espécies, muitas das quais podem habitar o trato gastrointestinal, sistema urogenital, pele, e mucosa do trato respiratório de seres humanos. Elas se tornam patogênicas em pacientes com o sistema imunológico comprometido e, nestas circunstâncias, podem causar doença em praticamente todos os órgãos e tecidos, resultando em infecção superficial, invasiva e sistêmica (Vieira; Santos, 2017).

De acordo com Siqueira et. al (2015), citado por Sobreira et. al (2020), na atualidade, o tratamento de candidíase consiste na administração de medicamentos, tanto tópicos quanto de uso sistêmicos, isolados ou associados, conforme manifestações clínicas. Porém, o aumento das espécies resistentes aos fármacos convencionalmente utilizados, bem como as elevadas taxas de mortalidade associadas, demanda a necessidade de desenvolvimento de alternativas terapêuticas mais eficazes (Vieira e Nascimento, 2017).

Existem tratados que demonstram a utilização de plantas medicinais que datam de 1700 a.C. para aplicação na saúde humana. Civilizações tais como a egípcia, chinesa, grega e romana têm descrições de tratados de espécies vegetais e dos usos. Na medicina popular as plantas medicinais podem ser utilizadas de várias formas, através de infusos, xaropes, unguentos e óleos voláteis (Glehn; Rodrigues, 2012). Nessa perspectiva, a utilização de plantas com potencial fitoterápico surge como uma importante ferramenta na indústria farmacêutica, uma vez que podem possuir uma atuação efetiva no combate a microrganismos oportunistas. 
Portanto, fica evidente que novos estudos envolvendo o desenvolvimento de fármacos antifúngicos são necessários, assim, a pesquisa teve como objetivo analisar a atividade antifúngica de extratos brutos dos vegetais Morinda citrifolia (None), Caryocar brasiliense (Pequi), Annona muricata (Graviola), Morus alba L. (Amora) e Apis mellífera L. (Própolis) frente a levedura Candida albicans.

\section{Metodologia}

\subsection{Coleta e identificação dos vegetais}

Espécimes dos vegetais None (Morinda citrifolia), Graviola (Annona muricata), Pequi (Caryocar brasiliense) e Amora (Morus alba L.) foram coletados no sítio São Joaquim, localizado na serra do Gavião a 25 km de Teresina-Piauí. Coletou-se uma porção de aproximadamente $1 \mathrm{~kg}$ dos vegetais, necessário à obtenção dos extratos brutos. A identificação das espécies dos vegetais fora realizada pelo botânico da Universidade Estadual do Maranhão-Caxias, Prof. Dr. Gonçalo Mendes da Conceição. Para tanto, partes específicas dos vegetais foram prensados, feitas exsicatas e depositadas no Herbário Aluízio Bittencourt pertencente ao LABIVE/UEMA/CESC.

\subsection{Obtenção dos extratos}

Os extratos foram adquiridos no Laboratório de Química da Faculdade Integral Diferencial (FACID), no qual todo o processo de obtenção se deu de acordo com as normas e recomendações da Farmacopeia Brasileira (2019). Logo após coleta, os espécimes foram postos para secagem à sombra, em ambiente arejado. A trituração dos vegetais foi realizada em moinho de facas até a condição de pó. Posteriormente, foi adicionado ao pó solvente metanol, onde ficou em repouso por 21 dias submetido a agitação diária. Após esse período, o material foi filtrado e depositado em um evaporador rotativo a $40^{\circ} \mathrm{C}$ para retirada de todo o solvente. Os órgãos utilizados para obtenção dos extratos foram a folha e o fruto da Graviola (Annona muricata), o fruto do None (Morinda citrifolia), a flor do Pequi (Caryocar brasiliense) e a casca da Amora (Morus alba L).

\subsection{Cepa fúngica}

Para a realização da pesquisa foi utilizada uma cepa de Candida albicans (ATCC-76485) adquirida comercialmente. A amostra foi reativada e cultivada em ágar Sabouraud-dextrose, com repiques sucessivos no Laboratório de Microbiologia e Imunologia da UniFacid, até utilização nos testes de susceptibilidade.

\subsubsection{Preparo dos meios de cultura}

As placas para os testes de suscetibilidade foram formadas de duas camadas compostas de ágar-ágar e ágar MullerHinton sucessivamente. A primeira camada foi constituída de 10,6 gramas do ágar diluídos em 300 ml de água destilada, de acordo com a recomendação do fabricante, posteriormente a mistura foi agitada suavemente e levada ao bico de Bunsen para a diluição completa do meio de cultura. Alíquotas de $15 \mathrm{ml}$ desse meio foram postas em tubos de ensaio e esterilizadas na autoclave em temperatura de $120^{\circ} \mathrm{C}$ por 15 minutos. Após a esterilização, as alíquotas foram entornadas em placas de Petri, com tamanho de 90 x 15 mm descartáveis esterilizadas (Pleion ®), as quais foram postas em repouso até solidificação do meio de cultura. Na segunda camada, composta de ágar Muller-Hinton, 3,6g de soluto foram diluídas em $300 \mathrm{ml}$ de água destilada. Alíquotas de $13 \mathrm{ml}$ desse meio foram postas em tubos de ensaio e esterilizadas na autoclave à temperatura de $120^{\circ} \mathrm{C}$ por 15 minutos. 


\subsubsection{Preparo do inóculo fúngico}

Mediante a utilização de uma alça de platina esterilizada foi realizada a inoculação das leveduras recentemente repicadas em tubos de ensaio com $1 \mathrm{ml}$ de soro fisiológico a $0,9 \%$, a turbidez da inoculação será obtida com base na escala 0,5 de Mac Farland (MF).

\subsection{Preparação das placas para a realização dos testes}

Para a preparação das placas para a realização do teste com extratos brutos, $1 \mathrm{ml}$ da suspensão microbiana foi adicionada aos $13 \mathrm{ml}$ de ágar Muller-Hinton, mantido à temperatura de $45^{\circ} \mathrm{C}$ no banho-maria. A segunda parte foi entornada sobre a primeira e poços foram confeccionados na segunda camada, mediante a utilização de ponteiras plásticas esterilizadas de 4,0 mm de diâmetros.

\subsection{Realização dos testes de suscetibilidade}

Os ensaios foram realizados em triplicata com a utilização da cepa de C. albicans ATCC-76485. A determinação da atividade antifúngica dos extratos foi realizada pela técnica da difusão em ágar em poços, segundo Groove e Randall (1955). Como controle positivo foi utilizado o antifúngico fluconazol, seguindo a padronização do Clinical and Laboratory Standards Institute (CLSI, 2019), e como controle negativo foi utilizado soro fisiológico esterilizado. A concentração do fluconazol como padrão de controle foi de $64 \mu \mathrm{g} / \mathrm{mL}$ (Höfling et al., 2010), diluído em DMSO.

Nos poços formados na segunda camada foram adicionados $40 \mu \mathrm{L}$ dos extratos testados, seguindo metodologia semelhante à de Alves et al., (2008). As placas foram incubadas a temperatura de $36^{\circ} \mathrm{C}$ em estufa de Demanda Bioquímica de Oxigênio (BOD) por um período de 48h. Após período de incubação foi realizada a leitura dos resultados, que ocorreu através da medição do diâmetro dos halos de inibição que foram formados. Os halos de inibição do crescimento microbiano foram medidos em milímetros, com auxílio de uma régua milimetrada, como o teste foi realizado em triplicata fora realizada uma média aritmética dos halos formados.

\subsection{Análise estatística}

As análises foram realizadas por meio dos programas estatísticos Bioestat 5.3 e R 4.0.3 (AYRES et al., 2007). Os dados obtidos em relação aos valores dos halos dos extratos brutos de Apis melífera L. (Propólis) e Caryocar brasiliense (Pequi) foram submetidos à análise de significância para verificar se haveria diferença significativa entre as médias dos valores de cada extrato, para isso foi utilizado o teste Shapiro-Wilk para análise de normalidade dos dados, quando comprovado que os dados não tinham distribuição normal foi aplicado o teste não paramétrico Mann-Whitney com o nível de significância de 5\% (p<0.05).

\section{Resultados}

Com base nos resultados obtidos, evidenciou-se que a $C$. albicans apresentou suscetibilidade aos extratos brutos dos vegetais Apis melífera L. (Propólis) e Caryocar brasiliense (Pequi), com média dos halos de suscetibilidade de $18 \mathrm{~mm}$ e $26 \mathrm{~mm}$ respectivamente e apresentou resistência a ação dos extratos de Morinda citrifolia L. (Noni), Morus alba L. (Amora) e Annona muricata L. (Graviola) (Tabela 1). 
Tabela 1 - Perfil de suscetibilidade de Candida albicans frente a extratos brutos de Apis melífera L. (Propólis), Caryocar brasiliense (Pequi), Morinda citrifolia L. (Noni), Morus alba L. (Amora) e Annona muricata L. (Graviola). Teresina-PI, 2021. $\mathrm{N}=05$.

\section{Extratos brutos dos vegetais}

\begin{tabular}{l|c|c|c|c|c} 
Cepa fúngica & $\begin{array}{l}\text { Apis melífera L. } \\
\text { (Propólis) }\end{array}$ & $\begin{array}{l}\text { Caryocar } \\
\text { brasiliense (Pequi) }\end{array}$ & $\begin{array}{l}\text { Morinda citrifolia L. } \\
\text { (Noni) }\end{array}$ & $\begin{array}{l}\text { Morus alba L. } \\
\text { (Amora) }\end{array}$ & $\begin{array}{l}\text { Annona muricata L. } \\
\text { (Graviola) }\end{array}$ \\
\hline $\begin{array}{l}\text { Candida } \\
\text { albicans }\end{array}$ & $18 \mathrm{~mm}$ & $26 \mathrm{~mm}$ & 0 & 0 & 0 \\
\hline
\end{tabular}

Fonte: Dados da pesquisa.

Os resultados obtidos na pesquisa demonstraram que os extratos brutos da Apis melífera L. e Caryocar brasiliense contêm na composição, elemento ou elementos com o poder de controlar o crescimento de C. albicans. Entretanto, ainda não podemos afirmar com segurança, que o perfil de suscetibilidade apresentado por essa fungos na pesquisa "in vitro" possa ser o mesmo "in vivo". Para termos a possibilidade da indicação desses vegetais como ferramenta auxiliar no controle de candidíase por $C$. albicans precisaríamos ter em mãos, o componente principal e responsável pela ação sobre esse fungo de forma purificado.

A busca de novas opções terapêuticas tem levado ao desenvolvimento de inúmeras pesquisas nos mais diversos segmentos das ciências. Essa busca incessante é devido ao alto grau de resistência que os microorganismos estão desenvolvendo frente aos mais diversos antimicrobianos utilizados no tratamento de infecções ocasionadas por bactérias ou fungos.

Considerando C. albicans, uma levedura que faz parte da microbiota normal dos humanos e que em certos momentos de fragilidade imunológica e outros, pode ocasionar infecção em humanos e que também tem desenvolvido resistência a alguns antifúngicos, é notória a procura de novas drogas que possam ser utilizadas no tratamento de pacientes acometidos por candidíases.

\section{Discussão}

As leveduras pertencente ao gênero Candida, em particular a C. albicans, são patógenos oportunistas frequentemente isolados das superfícies mucosas de indivíduos normais. Estão muito bem adaptadas ao corpo humano, por isso podem colonizá-lo sem produzir sinais de doença em condições de normalidade fisiológica. Essas infecções fúngicas variam desde lesões superficiais em pessoas sadias até infecções disseminadas em pacientes neutropênicos (Álvares et al., 2007).

Além disso, as leveduras fazem parte da microflora normal e as infecções invasivas surgem apenas quando ocorre o vazamento da barreira ou a função imunológica comprometida. Comparado às taxas de incidência de resistência em bactérias, resistência em Candida é um evento bastante raro, não é contagiosa e, portanto, isolados resistentes raramente são transferido de paciente para paciente. Ademais, mecanismos de resistência não podem ser transferidos via plasmídeos entre células de levedura. Consequentemente, resistência deve surgir em cada isolado durante a exposição antifúngica certamente, o que provavelmente é a razão do nível limitado de resistência exigida em uma perspectiva global (Arendrup, 2013).

Macroscopicamente, as colônias de Candida, no ágar Sabouraud-dextrose (SDA) usado rotineiramente, são de cor creme a amarela. Dependendo da espécie, a textura da colônia pode ser lisa, brilhante ou seca, ou enrugada e opaca. Sob condições padrão com nutrientes ideais, a levedura cresce em fase logarítmica como células que brotam (blastoconídios), de forma esférica a oval (Silva et al., 2012). 
Research, Society and Development, v. 10, n. 10, e440101019075, 2021

(CC BY 4.0) | ISSN 2525-3409 | DOI: http://dx.doi.org/10.33448/rsd-v10i10.19075

De acordo com Miranda et al. (2008), conforme citado por Silva et al. (2017) a fruta do C. brasiliense possui altas concentrações de antioxidantes como, vitamina E, carotenoides e compostos fenólicos. Sabe se que essas substâncias têm importante ação em algumas doenças, decorrente dos danos oxidativos. Nas folhas de $C$. brasiliense são encontradas grandes quantidades de compostos fenólicos, como flavonoides, que são conhecidos por propriedades farmacológicas como, antiinflamatória, antiviral, antialérgica e antioxidante, podendo explicar efetividade no tratamento. Além disso, conforme Yang et al. (2015), citado por Cesar et al. (2021), compostos como rutina, quercetina-3-glicosídeo, quercetina e kaempferol são exemplos de flavonoides presentes na folha da A. muricata que integram estudos relacionados aos seus efeitos farmacológicos.

No que diz respeito ao extrato de Apis melífera L., observa-se a formação de um halo de 18 milímetros de diâmetro, representando também uma atividade antifúngica em relação à $C$. albicans. Os flavonoides, juntamente com ácidos fenólicos e ésteres, aldeídos fenólicos e cetonas são considerados os mais importantes compostos antimicrobianos do própolis. Outros compostos são óleos voláteis e ácidos aromáticos (5 a 10\%), ceras (30-40\%), resinas, bálsamo e pólen que é uma rica fonte de elementos essenciais como magnésio, níquel, cálcio, ferro e zinco, apresentando assim muitas propriedades terapêuticas (Junior et al., 2005).

Acerca da C. albicans e o extrato de própolis (Apis melífera L.), as abelhas, a partir de coleta de material resinoso, gomoso ou balsâmico de botões de flores, sépalas e pétalas, folhas, caules e cascas de árvores, produzem esse material. Tratase de um forte adesivo, substância resinosa coletada, transformada e usada pelas abelhas (Apis mellifera L.) para selar frestas em suas colmeias, paredes internas e proteger a entrada contra intrusos (Burdock, 1998; Bruschi et al., 2002).

Preparações com própolis têm demonstrado atividades antimicrobianas in vitro frente a bactérias Gram-positivas e Gram-negativas, Helicobacter pylori, protozoários, fungos e vírus (Castaldo; Capasso, 2002). Em geral, bactérias Grampositivas são mais susceptíveis a própolis que Gram-negativas. Observou-se que $C$. tropicalis e $C$. albicans são suscetíveis à baixa concentração de própolis e, ainda, C. albicans apresentou maior suscetibilidade que C. tropicalis. (Sforcin et al., 2001).

Foram realizados vários estudos comprovando a atividade antimicrobiana do própolis, destacando-se por promover um tratamento potencialmente eficaz, seguro e de baixo custo. Atualmente, busca-se a ação localizada do fármaco pela utilização de sistemas mucoadesivos termossensíveis. (Pereira, 2011). Além disso, a utilização de sistemas microparticulados pode servir para controlar odores e sabores desagradáveis, proteger o fármaco da umidade ou oxidação, alterar a solubilidade, retardar a volatilização, remover solventes indesejáveis, para prevenir incompatibilidades e modificar a liberação (Bruschi $e t$ al., 2003, Bruschi, 2006, Andrews; Laverty; Jones et al., 2009).

Sobre a Morus alba L., é uma planta nativa da Ásia, conhecida como "amoreira branca", com grande importância na medicina popular chinesa. Foi introduzida no Brasil e tem sido bastante explorada do ponto de vista medicinal, inclusive comercialmente. Estudos vêm sendo realizados visando confirmar o potencial farmacológico dessa planta. Uma mistura de extratos padronizados de folhas de Uncaria gambir e casca da raiz de M. alba foi relatada como terapia alternativa para aliviar a osteoartrite e seus sintomas associados (Yimam et al., 2015).

Kim et al. (2003) relataram que extratos de folhas e frutos de M. alba foram capazes de reduzir os déficits cognitivos em ratos. Outros relatos mencionam atividades antioxidante, antibacteriana (Wang et al., 2012), antiviral (Lee et al., 2014) e neuroprotetora (See et al, 2015) de extratos e compostos isolados a partir de frutos, folhas, caule e raiz de M. alba. Outrossim, pesquisas recentes demonstraram o efeito protetor das folhas de Morus alba L., devido à presença de flavonoides baseadas na sua capacidade antioxidante, ação antiinflamatória e analgésica assim como a susceptibilidade antimicrobiana. (Nematbakhsh et al., 2013; Kalantari, Aghel \& Bayati, 2009). Dessa forma, a respeito de sua resposta antifúngica contra a C. albicans, a amora não apresenta atividade considerável nos estudos analisados aqui presentes. 
Segundo Wang e Su (2001), citado por Barbosa et al. (2016), o uso de Morinda citrifolia L., conhecida vulgarmente como: noni, índia mulberry, iada, nono, canary, Wood ou mengkudu, vem crescendo rapidamente no Brasil. Silveira et al. em um estudo sobre atividade antibacteriana dos frutos vendidos em feiras de São Luís, MA, verificaram que seus extratos hidroalcoólicos apresentaram ação contra Staphylococcus aureus. E Barani et al. e Jainkittivong et al. demonstraram in vitro a atividade antifúngica de extrato de suco do fruto liofilizado contra $C$. albicans. Também foi constatado que a atividade é variável segundo a concentração e o tempo de contato do extrato com o microrganismo (Oliveira et al., 2018, p.117).

Acerca da C. albicans e o extrato de Pequi (Caryocar brasiliense), Diniz (2015) mostrou em sua pesquisa que a aplicação do óleo de pequi em ferimentos pode ter seus efeitos farmacológicos otimizados quando este é elaborado farmacotecnicamente em forma de emulsão. Ademais, Borges (2011) menciona que o consumo do pequi tem sido associado a uma menor incidência e mortalidade por diversas doenças crônicas não transmissíveis em humanos. Assim, a proteção que esse alimento oferece contra doenças isquêmicas, cardíacas, cerebrovasculares e câncer, está associada aos constituintes químicos com propriedades antioxidantes.

O óleo possui atividade antifúngica, efeito tonificante e capacidade expectorante, sendo usado contra bronquites, gripes e resfriados e no controle de tumores. Segundo Passos et al., (2001), citado por Carvalho; Pereira; Araújo (2015) avaliaram a atividade antifúngica do pequi sobre Cryptococus neoformans var. neoformans e, constataram que todas as partes do fruto apresentavam atividade antifúngica, sendo que a cera retirada das folhas apresentavam atividades mais elevada, inibindo o crescimento de 91,3\% dos isolados do microorganismo. Ainda de acordo com Marques et al., (2002), também referenciado por Carvalho; Pereira; Araújo (2015), observaram que extratos metanólicos e etanólicos de folhas, botões florais, frutos (mesocarpo externo, mesocarpo interno e amêndoa) também têm efeito tóxico na germinação de esporos de Botrytis cinerea, Colletotrichum truncatum e Fusarium oxysporum.

Sobre a espécie vegetal Annona muricata L. (Annonaceae) pertencente ao gênero Annona, tem sido amplamente empregado no tratamento de inflamações, febres, infecções, diabetes e têm se mostrado potencialmente eficaz na terapia contra o câncer. Suas sementes são usadas com função emética e adstringente, e suas cascas como antidiabéticas e espasmolíticas (Lorenzi; Matos, 2002). As flores e também as folhas são utilizadas para tosse e problemas no trato respiratório inferior (Mors et al., 2000). As folhas da A. muricata são utilizadas na medicina popular por possuírem ações parasiticida, anti-reumática, antinevrálgica, adstringente e emética (de Carvalho et al., 2000). Além disso, uma das maiores descobertas sobre a graviola foi a sua capacidade de agir contra células cancerígenas, mostrando em testes de laboratório um potencial extraordinário; tal propriedade é consequência das acetogeninas presentes na graviola. Porém, a eficiência medicinal de um extrato vegetal não depende apenas de um único componente bioativo, mas do efeito sinergístico entre um composto principal e outros compostos secundários. Dessa forma, para se obter um extrato com excelente atividade biológica, deve-se levar em consideração o tipo de solvente utilizado, o procedimento de extração empregado e outros diversos fatores (local de cultivo, pH do solo, método de coleta, entre outros). (Vinatoru et al., 1997; Formiga, 2013). Em relação ao potencial antifúngico, a graviola não apresenta potencialidade contra a C. albicans nos estudos citados.

\section{Considerações Finais}

A pesquisa demonstrou que os extratos da fração metanólica do Apis melífera L. e do Caryocar brasiliense possuem atividade no controle de cepa de C. albicans, comprovando, assim, propriedades antifúngicas. Desse modo, é notório que os extratos medicinais ganham cada vez mais visibilidade, visto que possuem capacidade terapêutica comprovada "in vitro". 
Research, Society and Development, v. 10, n. 10, e440101019075, 2021 (CC BY 4.0) | ISSN 2525-3409 | DOI: http://dx.doi.org/10.33448/rsd-v10i10.19075

Contudo, notou-se que C. albicans não apresentou suscetibilidade aos extratos brutos dos vegetais Morus Alba L., Morinda citifoliaL. e Annona muricata L., não se fazendo necessário seguir por esse viés no que diz respeito a atividade anti $C$. albicans.

Vista disso, novas pesquisas são de grande valia para serem desenvolvidas e continuadas de forma mais avançada, utilizando-se o princípio ativo desses extratos com atividade anti $C$. albicans, uma vez que o potencial antifúngico pode ser testado frente a outros microorganismo. Dessa forma, pode-se aproveitar o potencial medicinal desses extratos e desfrutar de suas eficácias para serem utilizados com finalidades terapêuticas na indústria farmacêutica.

\section{Referências}

Aikawa, N. E., Rosa, D. T., Del Negro, G., Moraes, J. C., Ribeiro, A., Saad, C. G., ... \& Bonfá, E. (2016). Infecção sistêmica e localizada por Candida spp. em pacientes reumatológicos em terapia anti-TNF. Revista brasileira de reumatologia, 56, 478-482.

Barani, K., Manipal, S., Prabu, D., Ahmed, A., Adusumilli, P., \& Jeevika, C. (2014). Anti-fungal activity of Morinda citrifolia (noni) extracts against Candida albicans: An in vitro study. Indian Journal of Dental Research, 25(2), 188.

Cesar, K. K. F. A., Batista, A. K. R., Paula, L. R., da Silva, R. T., \& da Silva, F. L. (2021). Ação antifúngica de extratos e frações de Annona muricata L. sobre Candida spp. Research, Society and Development, 10(5), e28010514938-e28010514938.

de Cabral Sobreira, A. L., de Araújo Silva, M. M., Okamura, L. S., de Souza, J. B. P., \& Carmo, E. S. (2020). Atividade antifúngica do extrato etanólico de própolis vermelha contra isolados patogênicos de Candida spp. Revista Verde de Agroecologia e Desenvolvimento Sustentável, 15(4), 429-433.

Barbosa, A. F., Costa, I. C. D. M., Langassner, S. Z., \& Giordani, R. B. (2017). Morinda citrifolia: fatos e riscos sobre o u so do noni.

de Carvalho, L. S., Pereira, K. F., \& de Araújo, E. G. (2015). Características botânicas, efeitos terapêuticos e princípios ativos presentes no pequi (Caryocar brasiliense). Arquivos de Ciências da Saúde da UNIPAR, 19(2).

de Melo, I. A., \& Guerra, R. C. (2014). Candidíase oral: um enfoque sobre a estomatite por prótese. Salusvita, 33(3), 389-414.

de Oliveira, F. C. E., Silva, L. B. P., Abranches, M. V., \& Ferreira, A. A. (2018). Efeitos terapêuticos e adversos do noni (morinda citrifolia 1.) Na saúde. Revista Saúde \& Ciência Online, 7(3), 107-122.

Diniz, D. M. (2015). Atividade anti-inflamatória de microemulsão contendo óleo de pequi (Caryocar coriaceum W.). 2015. 37f. Trabalho de Conclusão de Curso (Graduação em Farmácia)-Universidade Estadual da Paraíba, Campina Grande.

Fernandes Júnior, A., Lopes, M. M. R., Colombari, V., Monteiro, A. C. M., \& Vieira, E. P. (2006). Atividade antimicrobiana de própolis de Apis mellifera obtidas em três regiões do Brasil. Ciência Rural, 36, 294-297.

Glehn, E. A. V., \& Rodrigues, G. P. S. (2012). Antifungigrama para comprovar o potencial de ação dos extratos vegetais hidroglicólicos sobre Candida sp.(Berkhout). Revista Brasileira de Plantas Medicinais, 14, 435-438.

Lee, J. H., Bae, S. Y., Oh, M., Kim, K. H., \& Chung, M. S. (2014). Antiviral effects of mulberry (Morus alba) juice and its fractions on foodborne viral surrogates. Foodborne pathogens and disease, 11(3), 224-229.

Martins, N., Barros, L., Henriques, M., Silva, S., \& Ferreira, I. C. (2015). In vivo anti-candida activity of phenolic extracts and compounds: Future perspectives focusing on effective clinical interventions. BioMed research international, 2015.

Moraes-Pinto, M. I. D., \& Ferrarini, M. A. G. (2020). Infecções oportunistas em pediatria: quando suspeitar e como abordar. Jornal de Pediatria, 96, 47-57.

Seo, K. H., Lee, D. Y., Jeong, R. H., Lee, D. S., Kim, Y. E., Hong, E. K., ... \& Baek, N. I. (2015). Neuroprotective effect of prenylated arylbenzofuran and flavonoids from Morus alba fruits on glutamate-induced oxidative injury in HT22 hippocampal cells. Journal of Medicinal Food, $18(4), 403-408$.

Silva, G. C. D. (2015). Morinda Citrifolia L.-investigação científica das propriedades biológicas com base no uso popular (Master's thesis, Universidade Federal de Pernambuco).

Silva, E., DA, M., Rodrigues, L., \& Silva Neto, C. D. M. (2017). Avaliação da capacidade inibitória de Caryocar brasiliense E Stryphnodendron adstringens sobre Candida albicans.

Vieira, A. J. H., \& Santos, J. I. (2017). Mecanismos de resistência de Candida albicans aos antifúngicos anfotericina B, fluconazol e caspofungina. $R B A C, 49(3), 235-9$.

Vieira, F., \& Nascimento, T. (2017). Candida antifungal resistance and therapeutic approach. Revista Portuguesa de Farmacoterapia, 9(3), 29-36.

Vieira, J. Candidíase-uma revisão de literatura.

Yimam, M., Lee, Y. C., Kim, T. W., Moore, B., Jiao, P., Hong, M., ... \& Jia, Q. (2015). UP3005, a botanical composition containing two standardized extracts of Uncaria gambir and Morus alba, improves pain sensitivity and cartilage degradations in monosodium iodoacetate-induced rat OA disease model. EvidenceBased Complementary and Alternative Medicine, 2015. 